Check for updates

Cite this: RSC Adv., 2019, 9, 15141

\title{
Hybrid MIL-101(Cr)@MIL-53(Al) composite for carbon dioxide capture from biogas $\dagger$
}

\author{
Armin Taheri, (D) *a Ensieh Ganji Babakhani, ${ }^{\text {b }}$ Jafar Towfighi Darian (D) b \\ and Saeed Pakseresht ${ }^{\mathrm{C}}$
}

In this study, hybrids of nanoporous MIL-101(Cr) and MIL-53(Al) were synthesized using a hydrothermal method for various time periods, ranging from 8 to $40 \mathrm{~h}$. The prepared materials were characterized by powder X-ray diffraction (PXRD) and elemental analysis, and their specific surface areas were measured by $\mathrm{N}_{2}$ sorption at $77 \mathrm{~K}$ using the Brunauer-Emmett-Teller (BET) method. To investigate the practical application of these materials, the pure carbon dioxide and methane adsorption capacities of the samples were determined using the volumetric method. The Langmuir model was used to fit the $\mathrm{CO}_{2}$ and $\mathrm{CH}_{4}$ isotherms. Extended Langmuir (EL) equations and the ideal adsorbed solution theory (IAST) models were used to obtain the $\mathrm{CO}_{2} / \mathrm{CH}_{4}$ selectivity. The sample with the highest BET specific surface area was selected as a candidate for further investigations. The thermal stability of the selected sample was investigated by thermogravimetric analysis (TGA). Scanning electron microscopy (SEM) was used to characterize the sample morphology. XRD results showed that the sample synthesized over the shortest time corresponded to MIL-101(Cr), while the sample synthesized over the longest time was in agreement with MIL-53(Al). Samples synthesized for time periods between these two limits were assumed to be composites of both MIL-53(Al) and MIL-101(Cr). TGA results indicated that the hybrid materials were thermally stable at temperatures about $100{ }^{\circ} \mathrm{C}$ higher than for pure MIL-101(Cr). The BET specific surface area $\left(1746 \mathrm{~m}^{2} \mathrm{~g}^{-1}\right)$ and $\mathrm{CO}_{2}$ adsorption capacity $\left(16 \mathrm{mmol} \mathrm{g}{ }^{-1}\right)$ of the selected hybrid sample were about $50 \%$ and $35 \%$ higher, respectively, compared with those of pure MIL-53(Al), but $30 \%$ and $20 \%$ lower, respectively, compared with those of pure MIL-101(Cr). Binary adsorption modeling showed the high selectivity of the MIL-101(Cr) and MIL-53(Al) hybrid material for $\mathrm{CO}_{2}$ with a minimum separation factor of about 60 at $298 \mathrm{~K}$. This value was much higher than those reported previously and those observed in this work for the original MIL-101(Cr) or MIL-53(Al). These results demonstrated that the hybrid of MIL$101(\mathrm{Cr})$ and $\mathrm{MIL}-53(\mathrm{Al})$ was a promising material for selective $\mathrm{CO}_{2}$ capture from natural and biogas.

Received 28th December 2018 Accepted 29th April 2019

DOI: $10.1039 / c 8 r a 10619 c$

rsc.li/rsc-advances
Adsorption-based processes are cost-effective technologies that have recently found many applications in separation and purification processes. ${ }^{4}$

Many adsorbent materials that have been developed for $\mathrm{CO}_{2}$ capture, such as activated carbon, zeolites, and zeolite-like materials. A suitable adsorbent for $\mathrm{CO}_{2}$ capture should satisfy several important criteria to compete with present sorbents, including high adsorption capacity, high $\mathrm{CO}_{2}$ selectivity, adequate adsorption/desorption kinetics, good regeneration stability, mechanical strength during repeated adsorption/ desorption cycles, and low operating costs.

In recent years, hybrid materials known as metal-organic frameworks (MOFs) have been introduced in many applications, such as catalysis, ${ }^{5}$ drug delivery, ${ }^{6}$ and gas separation/ purification and storage, owing to their advantages over available commercial adsorbents. ${ }^{7}$ These MOFs comprise metal ions (or metal cluster) and organic ligands linked by coordination bonds. Their most important advantages are a high permanent porosity, uniform pore size, and high specific surface area. ${ }^{\mathbf{8 9}}$

\footnotetext{
${ }^{a}$ Young Researchers and Elites Club, Science and Research Branch, Islamic Azad University, Tehran, Iran.E-mail: armin.taheri@gmail.com; armin_taheri@alum. sharif.edu

${ }^{b}$ Gas Department, Research Institute of Petroleum Industry (RIPI), Tehran, Iran ${ }^{c}$ Research \& Technology Directorate of National Iranian Gas Company, Iran

$\dagger$ Electronic supplementary information (ESI) available. See DOI: 10.1039/c8ra10619c
} 
However, some disadvantages, such as low water and thermal stability, and easier catenation of frameworks, have been reported. The self-assembly of two or more frameworks within each other in a structure, which leads to the physical (but not chemical) interconnection of the frameworks, is called catenation. $^{\mathbf{1 0}}$

MIL-101 and MIL-53 (MIL stands for Materials Institute of Lavoisier) are well-known MOFs owing to their interesting properties. ${ }^{11-14}$ MIL-53, which has a chemical formula of $\mathrm{M}(\mathrm{OH})$ $\left[\mathrm{C}_{6} \mathrm{H}_{4}\left(\mathrm{CO}_{2}\right)_{2}\right]_{3} \cdot n \mathrm{H}_{2} \mathrm{O}\left(\mathrm{M}=\right.$ metal ion), comprises $\mathrm{MO}_{4}(\mathrm{OH})_{2}$ corner-sharing octahedral chains linked by terephthalate groups to form a three-dimensional structure. MIL-53 has an orthorhombic structure with a pore volume of $0.6 \mathrm{~cm}^{3} \mathrm{~g}^{-1}$ and a pore size of $0.85 \mathrm{~nm} .^{\mathbf{1 3 , 1 5 , 1 6}}$ Syntheses of MIL-53 with trivalent metal cations, such as $\mathrm{Al}^{3+}, \mathrm{Cr}^{3+}, \mathrm{Fe}^{3+}, \mathrm{Ga}^{3+}, \mathrm{Sc}^{3+}$, and $\mathrm{In}^{3+}$, have been reported. ${ }^{17}$

MIL-101 is composed of carboxylic linkers that connect a trimeric building unit with a chemical formula of $\mathrm{M}_{3} \mathrm{O}(\mathrm{F} /$ $\mathrm{OH})\left(\mathrm{H}_{2} \mathrm{O}\right)_{2}\left[\mathrm{C}_{6} \mathrm{H}_{4}\left(\mathrm{CO}_{2}\right)_{2}\right]$ with a cubic structure. MIL-101 contains two types of cage that can be accessed through a pentagonal window $(\sim 1.2 \mathrm{~nm})$ for the $2.9 \mathrm{~nm}$ cage and hexagonal windows $(\sim 1.4-1.6)$ for the $3.4 \mathrm{~nm}$ cage. ${ }^{11,16}$ MIL-101 has been synthesized with $\mathrm{Cr}^{3+}, \mathrm{V}^{3+}$, and $\mathrm{Ti}^{3+} \cdot \mathbf{. 1 8}^{\mathbf{1 8 - 2 0}}$

MIL-101(Cr) and MIL-53(Cr) have been synthesized from the same reaction mixture with a different water composition. ${ }^{\mathbf{1 8 , 2 1}}$ However, in the early reaction stages, the rate of MIL-53 formation is slower than that of MIL-101, while MIL-53 formation increases with reaction time.

The presence of coordinatively unsaturated sites (CUSs or open metal sites) plays a key role in selective adsorption on MOFs from gas mixture. The excellent separation performance of MIL-101 is thought to be related to the existence of a CUS that acts as a Lewis acid site. ${ }^{\mathbf{1 8 , 2 2 - 2 6}}$

MIL-101(Cr) is a highly porous MOF with a mesopore internal volume and high specific surface area among MOFs and acidic open metal sites (CUSs). ${ }^{\mathbf{1 8 2 6 - 2 8}}$ MIL-53(Al) shows marked thermal stability $\left(500{ }^{\circ} \mathrm{C}\right)$ among MOFs, which are typically limited to $400{ }^{\circ} \mathrm{C}$, and is prepared from relatively cheap and available raw materials. MIL-53(Al) is also moisture resistant and has a relatively high specific surface area. ${ }^{29-32}$

A composite of MIL-101(Cr) and MIL-53(Al) can benefit from the advantages of both materials for industrial applications. Therefore, this possibility has been investigated through simultaneous synthesis of MIL-101(Cr) and MIL-53(Al) raw materials in the same reaction container. In general, a material composed of one or more distinct MOF components is known as a composite or hybrid, wherein the advantages of both MOFs can be effectively unified. ${ }^{33}$

To our knowledge, there is no published research on the synthesis and application of MIL-101(Cr) and MIL-53(Al) composites for gas separation.

For adsorption-based $\mathrm{CO}_{2}$ capture by MOFs, it has been suggested that MOFs could be designed to selectively enhance $\mathrm{CO}_{2}$ interactions with the framework while limiting $\mathrm{CH}_{4}$ uptake. ${ }^{34}$ This study aimed to synthesize hybrid materials of MIL-101(Cr) and MIL-53(Al) for $\mathrm{CO}_{2}$ adsorption. The synthesized materials were characterized by powder X-ray diffraction
(PXRD), elemental analysis, and the Brunauer-Emmett-Teller (BET) method. The $\mathrm{CO}_{2}$ and $\mathrm{CH}_{4}$ adsorption of the obtained materials were measured using the volumetric method and were fitted to the Langmuir model. The selectivity for $\mathrm{CO}_{2} / \mathrm{CH}_{4}$ adsorption from their binary mixture was evaluated using the extended Langmuir (EL) and ideal adsorbed solution theory (IAST) models. The thermal stability of the selected sample was measured by thermogravimetric analysis (TGA). The morphology of the selected sample was characterized by scanning electron microscopy (SEM).

\section{Materials and methods}

$\mathrm{Al}\left(\mathrm{NO}_{3}\right)_{3} \cdot 9 \mathrm{H}_{2} \mathrm{O}, \mathrm{Cr}\left(\mathrm{NO}_{3}\right)_{3} \cdot 9 \mathrm{H}_{2} \mathrm{O}, 1$,4-benzenedicarboxylic acid (denoted as BDC, 98\%, Sigma-Aldrich) and hydrogen fluoride (HF, 98\%, Sigma-Aldrich) were used in this study.

MIL-53(Al) and MIL-101(Cr) were synthesized according to a literature procedure and were denoted as s7 and s1, respectively. MIL-53 and MIL-101 were synthesized from mixtures with the following molar ratios: $\mathrm{Al} / \mathrm{BDC} / \mathrm{H}_{2} \mathrm{O}=1: 0.5: 80$ and $\mathrm{Cr} /$ $\mathrm{BDC} / \mathrm{HF} / \mathrm{H}_{2} \mathrm{O}=1: 1: 1: 180$.

Hybrid materials of MIL-101 and MIL-53 were synthesized by modifying the literature procedures. ${ }^{18,29}$ A reactant mixture with an $\mathrm{Al} / \mathrm{Cr} / \mathrm{BDC} / \mathrm{HF} / \mathrm{H}_{2} \mathrm{O}$ molar ratio of $1: 1: 3: 1: 300$ was used. The hydrophobic part of the ligand, which constructs the pore wall, reportedly tends to be small to prevent unfavorable contact with water molecules. ${ }^{29}$ Therefore, excess BDC was used, firstly, to occupy the pore with hydrophobic interaction to promote larger pore formation and, secondly, to minimize the presence of unreacted metal ions. The removal of unreacted metal ions as an impurity is difficult, but BDC can simply be removed by calcination or solvent extraction. ${ }^{35}$

Initially, the $\mathrm{Cr} / \mathrm{BDC} / \mathrm{HF} / \mathrm{H}_{2} \mathrm{O}$ mixture was loaded into a Teflon-lined stainless steel reactor and mixed at $80{ }^{\circ} \mathrm{C}$ for about $1 \mathrm{~h}$. Aluminum nitrate was then added to the reaction mixture, followed by stirring for $30 \mathrm{~min}$, and then the mixture was heated to $220{ }^{\circ} \mathrm{C}$ in the sealed autoclave. The mixture was allowed to react for different times (8, 16, 24, 32, and $40 \mathrm{~h})$, with the samples denoted as s2, s3, s4, s5 and s6, respectively. All synthesis conditions for these samples were the same, except the reaction time. At the end of the reaction, the autoclave was cooled to room temperature and the resulting powder was filtered and purified using a two-stage solvent extraction method with DMF and ethanol. ${ }^{35}$ Finally, the purified material was calcined in a hot air stream.

The obtained materials were characterized by PXRD analysis at ambient temperature using a PHILIPS PW-1840 X-ray diffractometer equipped with $\mathrm{Cu} \mathrm{K} \alpha$ radiation $(k=0.154 \mathrm{~nm})$. $\mathrm{N}_{2}$ gas at $77 \mathrm{~K}$ and up to 1 bar was used for the BET method specific surface area measurements, conducted by a Micromeritics TriStar II analyzer. Sample outgassing and activation were performed at $493 \mathrm{~K}$ in situ for $4 \mathrm{~h}$ under vacuum pressure. The pore size distribution (PSD) of the samples was derived from $\mathrm{N}_{2}$ isotherms using the Halsey-Faas correction. The sample adsorption capacities for $\mathrm{CO}_{2}$ and $\mathrm{CH}_{4}$ gases were determined using the conventional volumetric method. TGA (Mettler-Toledo) was used to determine the thermal stability of 
the as-synthesized s4 material with a heating rate of $10{ }^{\circ} \mathrm{C} \min ^{-1}$ under air flow. The sample morphology was observed by SEM using a HITACHI S4160 FESEM instrument. Chemical compositions of the synthesized materials were determined using ICP (inductively coupled plasma; OPTIMA 4300DV, PerkinElmer) and $\mathrm{CHN}-\mathrm{O}$ (EA, Heraeus) analyzers.

\section{Results and discussion}

\subsection{PXRD}

The PXRD patterns of all samples are shown in Fig. 1. The PXRD patterns of s1 and s2 showed relatively good agreement with that of MIL-101(Cr), while those of s6 and s7 were comparatively closely matched with that of MIL-53(Al) reported previously. ${ }^{\mathbf{1 8 , 2 9}}$ For other samples (s3-s5) a combination of major MIL-101(Cr) and MIL-53(Al) peaks was observed. Therefore, the obtained hybrid material synthesized with the lowest time duration (s2) was matched to MIL-101(Cr), while the hybrid sample obtained at the highest duration (s6) was in agreement with MIL-53(Al). Materials synthesized at time durations between these two limits were assumed to be composites of the two MOFs and had XRD patterns with representative peaks of both MIL-53(Al) and MIL-101(Cr). As the synthesis time increased, major peaks of MIL-101(Cr) disappeared and major peaks of MIL-53(Al) became sharper and more intense. A small displacement in the peak positions compared with the original MIL-53(Al) and MIL-101(Cr) was observed, which might be attributed to the distortion force of the two structures.

MIL-101 was obtained selectively if the $\mathrm{H}_{2} \mathrm{O} / \mathrm{Cr}$ molar ratio was greater than 500, or MIL-53 was obtained selectively if the $\mathrm{H}_{2} \mathrm{O} / \mathrm{Cr}$ molar ratio was less than $200 .^{36}$ Therefore, in this study, at a $\mathrm{H}_{2} \mathrm{O}$ / $\mathrm{Cr}$ molar ratio of 300, neither MOF was formed selectively and the synthesis time controlled the yields of MIL-101(Cr) or MIL-53(Al) formation. Therefore, MIL-101(Cr) PXRD peaks were detected in the PXRD pattern of sample s2 (with the shortest synthesis time). MIL-53(Al) PXRD peaks appeared with increasing time (s3-s6), which might be related to the formation of MIL-53 within the MIL-101 structure and could be attributed to the conversion of MIL-101 secondary building units (SBUs) into MIL-53 SBUs. An SBU is an MOF subunit in which the ligand and metal cluster produce a complex through coordination bonds. ${ }^{37}$ Porous networks act as a template for the growth of duplicated frameworks. ${ }^{38}$ As the void space of MIL-101 included enough free volume to host an additional SBU, a second independent MOF (MIL-53) was formed. Therefore, with a longer synthesis time, MIL-101 was decomposed and MIL-53 was formed. Notably, MIL101 was assumed to be less stable than MIL-53. The conversion of MIL-101 into MIL-53 during the reaction has been confirmed previously by some researchers. ${ }^{16}$

Notably, the relative synthesis rate of MIL-53(Al) is much higher (about 31-fold) than that of MIL-53(Cr) ${ }^{39}$ Therefore, MIL53(Al) would be obtained as the synthesis time increased.

Some additional peaks were observed in the sample XRD patterns that were attributed to the presence of impurities, particularly deformed BDC.

\section{$3.2 \mathrm{~N}_{2}$ sorption}

The $\mathrm{N}_{2}$ sorption isotherms of the synthesized materials at $77 \mathrm{~K}$ are shown in Fig. 2. The BET method was used to estimate the specific surface areas, pore volumes, and pore sizes of the samples from $\mathrm{N}_{2}$ isotherms. The obtained BET specific surface areas and pore volumes are shown in Table 1.

As shown in Fig. 2, the isotherms of s1 (MIL-101) and s2 were type IV according to the IUPAC (International Union of Pure and Applied Chemistry) classification, ${ }^{\mathbf{4 0}}$ and showed hysteresis loops upon desorption, which was attributed to capillary condensation

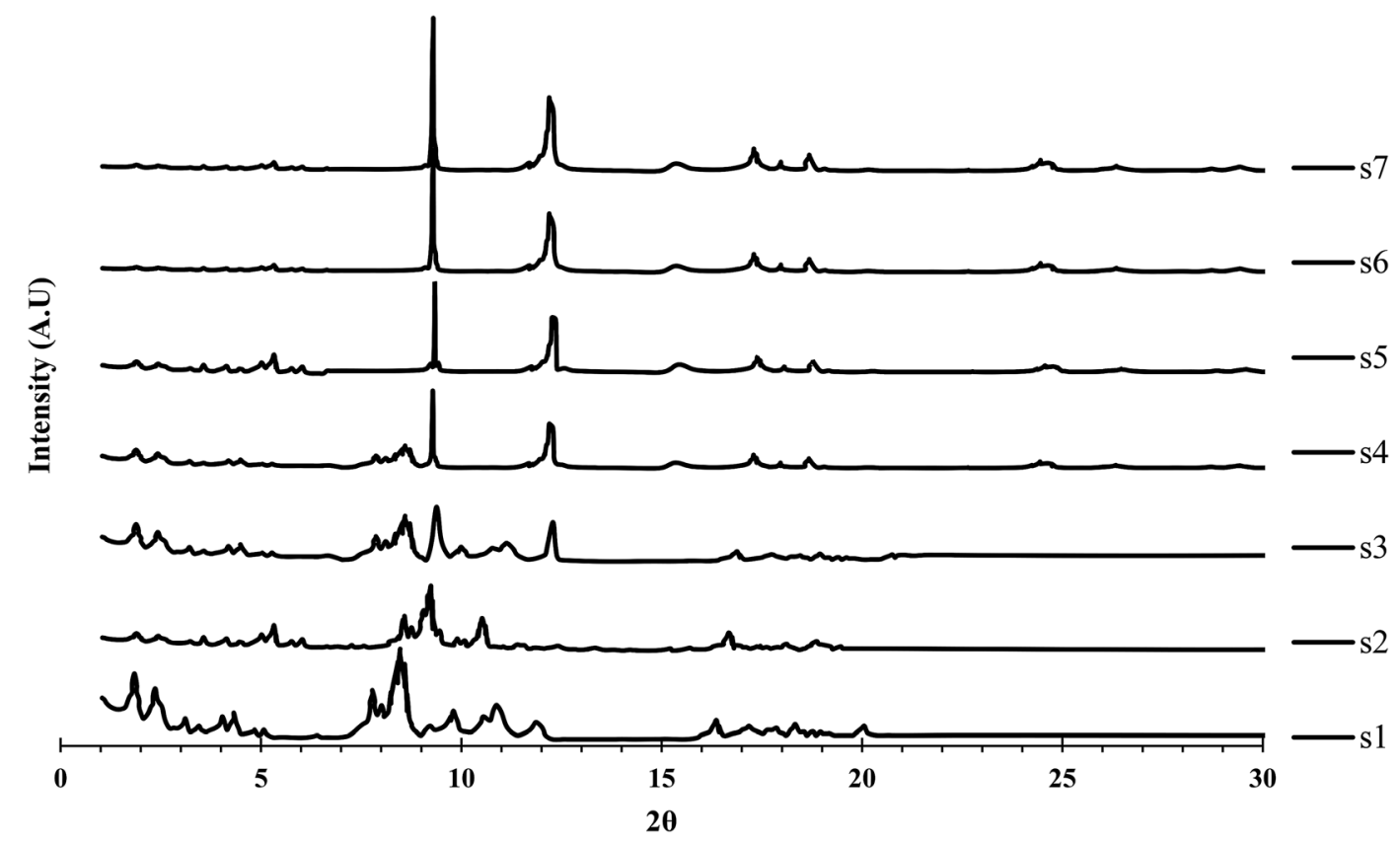

Fig. 1 PXRD patterns of the samples. 


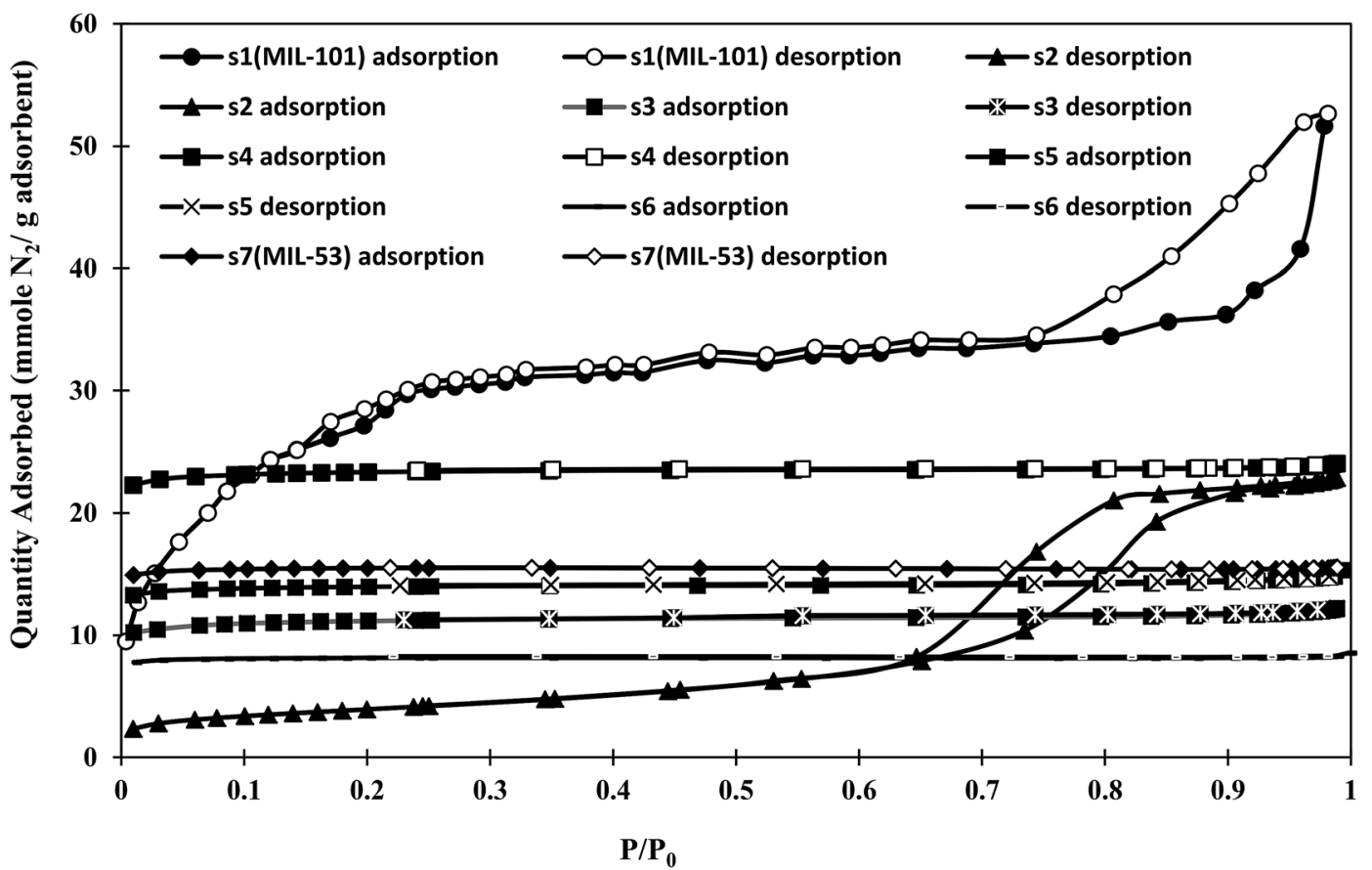

Fig. 2 Isotherms of nitrogen adsorption and desorption at $77 \mathrm{~K}$ up to $1 \mathrm{bar}$.

in their mesoporous structures. The initial part of the isotherm was similar to a type I isotherm, related to microporous filling. Sample s1 showed strong interparticle porosity, with capillary condensation above $P / P_{0}=0.95$, while sample s2 was similar to SBA-15, with capillary condensation steps above $P / P_{0}=0.75$ and a clear $\mathrm{H} 1$ hysteresis loop. ${ }^{41}$ The other samples were classified as type I, corresponding to microporous materials. According to Table 1, the lower BET specific surface area of sample s2 with respect to pure MIL-101 (s1) might be related to the pore filling effects of unreacted metal ions or newly formed metal clusters of MIL-53, and the interaction of open metal sites of MIL-101 through coordination bonds. An increasing specific surface area was observed with increasing synthesis time for samples s2-s4. This was attributed to the formation of MIL-53 (as observed in the XRD pattern in Fig. 1 and SEM images in Fig. 8). The highest BET specific surface area among the hybrid samples was about $1746 \mathrm{~m}^{2}$ $\mathrm{g}^{-1}$ for $\mathrm{s} 4$. Sample s4 showed an approximately $50 \%$ enhancement in BET specific surface area compared with that of MIL-53 (s7), but an approximately $20 \%$ decrease compared with that of MIL-101 (s1). As the synthesis time increased, the BET specific surface area of the samples increased, reaching a maximum at a certain time.

The low BET specific surface areas of s5 and s6 might result from the decomposition of MIL-101(Cr), as observed in the PXRD patterns. With long synthesis times, the entrances of some pores might be blocked or limited, excluding nitrogen molecules. Therefore, the adsorption capacity was limited to accessible pores.

The pore size distribution of s4 as the selected sample was compared with those of MIL-101 (s1) and MIL-53 (s7) as shown in Fig. 3. Sample s4 was selected due to possessing the highest BET specific surface area among the hybrid samples. Two types of a pore (mesopores and micropores) were observed in the structure of s1, while the structures of s4 and s7 were mostly microporous.

\section{3 $\mathrm{CO}_{2}$ and $\mathrm{CH}_{4}$ adsorption}

Fig. 4 and 5 show the adsorption isotherms of $\mathrm{CO}_{2}$ and $\mathrm{CH}_{4}$ at ambient temperature. The $\mathrm{CH}_{4}$ isotherms of all samples and the $\mathrm{CO}_{2}$ isotherms of s1 and s2 were classified as the usual type I, according to the IUPAC classification, while a type IV isotherm was observed in the $\mathrm{CO}_{2}$ adsorption isotherm profiles of samples $\mathbf{s} 3-\mathbf{s 7 . ^ { 4 0 }}$ The steps in these isotherm curves were attributed to the structural transition of MIL-53, which resulted from the breathing effect. MIL-53 series existed in two forms, but with the same topology, including a narrow-pore (NP) form with rectangular pores $(0.85 \times 0.85 \mathrm{~nm})$, and a large-pore $(\mathrm{LP})$ form with trapezoidal pores $(0.26 \times 1.36 \mathrm{~nm})$. Reversible structural transformations from the LP form to the NP from were observed upon adsorption of some polar guest molecules, such as $\mathrm{CO}_{2}, \mathrm{H}_{2} \mathrm{O}$, and $\mathrm{H}_{2} \mathrm{~S}$, known as the breathing effect. This phenomenon has not been reported for MIL-101. ${ }^{42}$ Therefore,

Table 1 BET specific surface areas of the samples

\begin{tabular}{|c|c|c|c|c|c|c|c|}
\hline Sample & s1(MIL-101) & s2 & s3 & s4 & s5 & s6 & s7(MIL-53) \\
\hline BET surface area $\left(\mathrm{m}^{2} \mathrm{~g}^{-1}\right)$ & 2254 & 439 & 1039.6 & 1745.8 & 1113.5 & 606.3 & 1153.7 \\
\hline Total pore volume $\left(\mathrm{m}^{3} \mathrm{~g}^{-1}\right)$ & 1.18 & 0.29 & 0.51 & 0.80 & 0.52 & 0.32 & 0.55 \\
\hline Micropore volume $\left(\mathrm{m}^{3} \mathrm{~g}^{-1}\right)$ & 0.62 & 0.19 & 0.36 & 0.72 & 0.49 & 0.31 & 0.51 \\
\hline
\end{tabular}




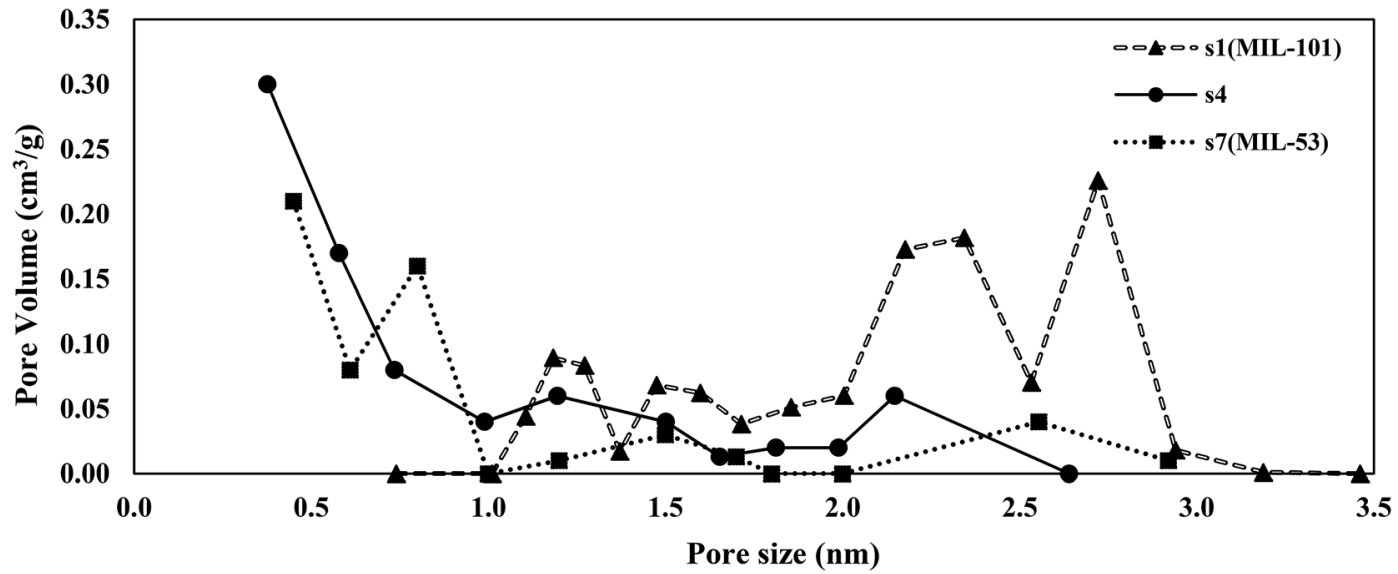

Fig. 3 Pore size distributions (PSDs) of s1 (MIL-101), s4 (hybrid), and s7 (MIL-53).

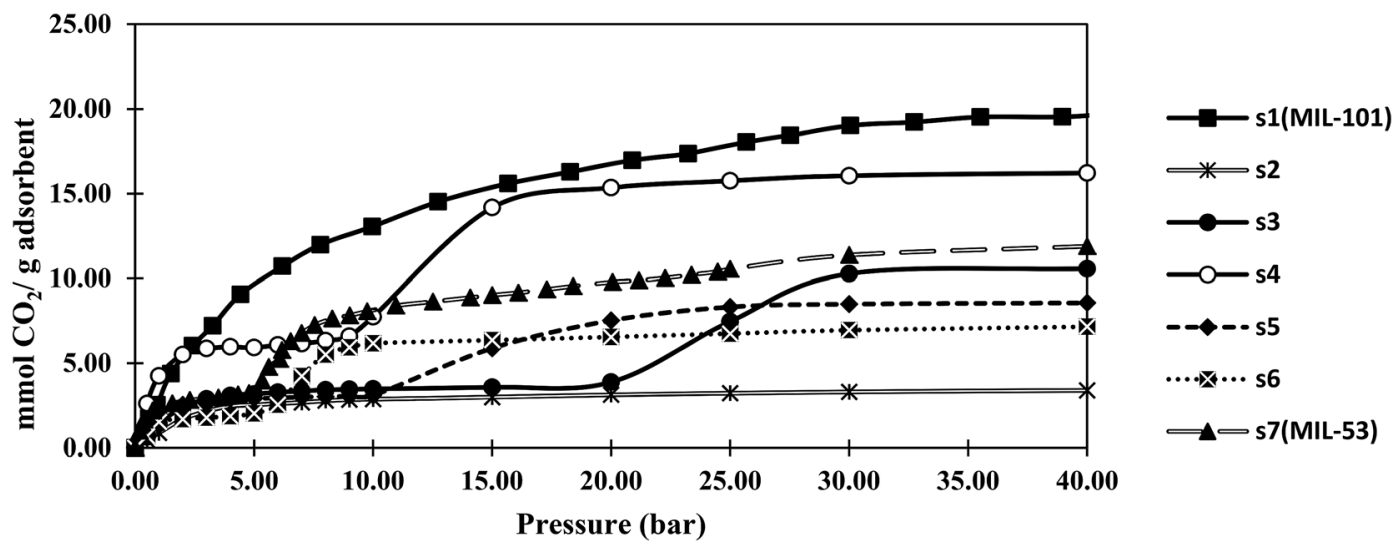

Fig. 4 Isotherms of carbon dioxide adsorption at ambient temperature.

the breathing effect was not observed in s1 and s2, which contained only the MIL-101 structure according to the PXRD results.

Notably, the maximum adsorption capacities of samples s1 (MIL-101) and s7 (MIL-53) were rather similar to those reported for MIL-101(Cr) ${ }^{43}$ and MIL-53(Al) ${ }^{44}$ by other researchers.

The $\mathrm{CO}_{2}$ and $\mathrm{CH}_{4}$ capacities of $\mathrm{s} 2$, which was similar to MIL101, were lower than those of the original MIL-101 (s1). This might be due to $\mathrm{s} 2$ having a lower specific surface area than that of s1, and/or the existence of formed metal clusters that coordinated with the open metal sites of MIL-101. MOF pores have been shown to capture nanoparticles, such as single metal or metal cluster nanoparticles, within their channels. ${ }^{4,46}$ Metal/ metal cluster nanoparticles were observed with darker contrast in the TEM image of s2 compared with that of s1 (Fig. S1†).

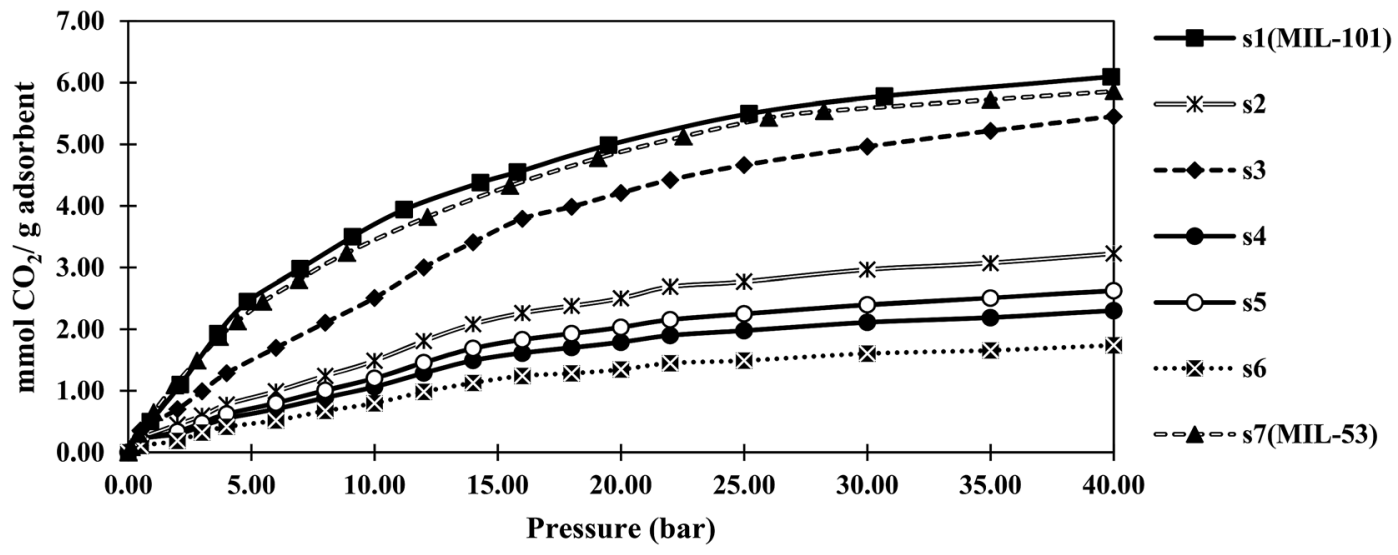

Fig. 5 Isotherms of methane adsorption at ambient temperature. 
Table 2 Adjustable parameter of the Langmuir equation

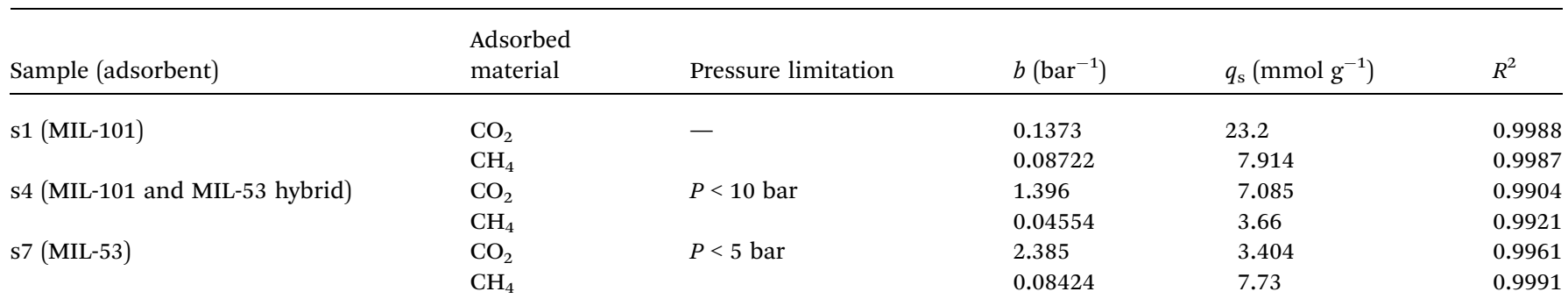

The $\mathrm{CO}_{2}$ adsorption capacities of the samples followed the same trend as that observed in the BET specific surface area experiments. This was ascribed to proportional relation between the BET surface area and $\mathrm{CO}_{2}$ adsorption capacity, as reported for MOFs. $^{3,47}$ Furthermore, in hybrid samples, electrostatic interactions between the adsorbent and adsorbate were increased. Therefore, the adsorbate was trapped in a van der Waals interaction with the adsorbent, resulting in a higher adsorption capacity.

Sample s4, which had the highest BET specific surface area among the hybrid samples, showed a $\mathrm{CO}_{2}$ capacity of about
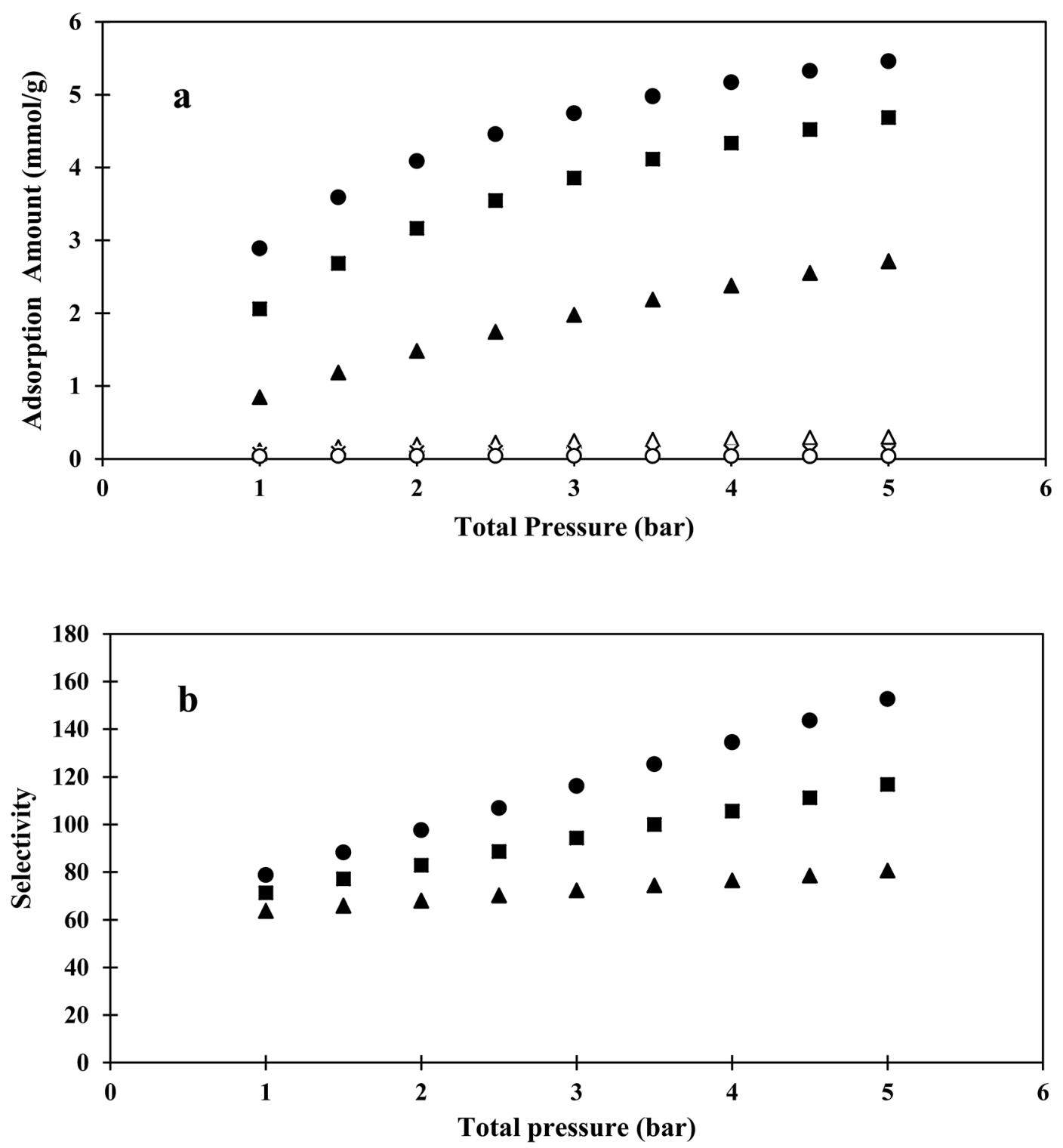

Fig. 6 (a) Binary adsorption isotherm of $\mathrm{CH}_{4}$ (empty shape) and $\mathrm{CO}_{2}$ (filled shape), and (b) $\mathrm{CO}_{2} / \mathrm{CH}_{4}$ selectivity (using IAST as a function of pressure and molar composition (50\% circle, 30\% square, and 10\% triangle) at ambient temperature (298 K) for sample s4). 


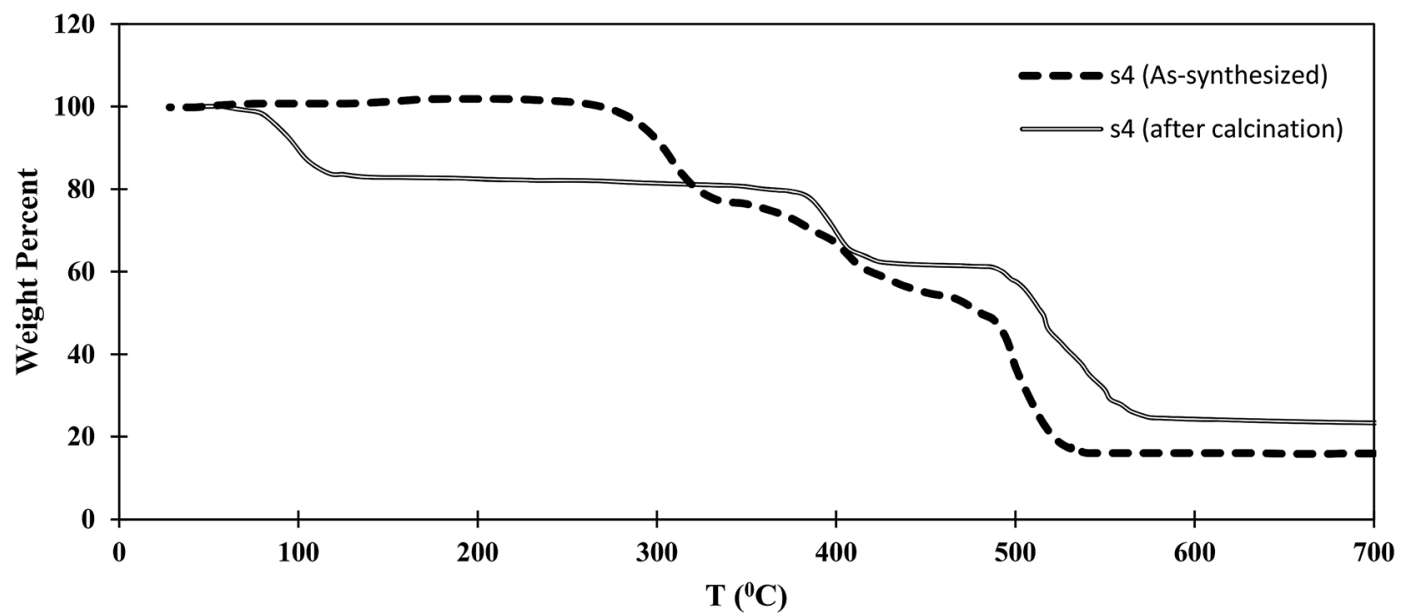

Fig. 7 TGA curve of sample s4.

$16 \mathrm{mmol} \mathrm{g}^{-1}$ at 40 bar. This capacity was more than that of MIL$53\left(12 \mathrm{mmol} \mathrm{g}^{-1}\right)$, but lower than that of MIL-101 $\left(20 \mathrm{mmol} \mathrm{g}^{-1}\right)$. The results showed that hybrid $\mathrm{s} 4$ afforded an enhancement of about $35 \%$ in the gravimetric adsorption of $\mathrm{CO}_{2}$ compared with MIL-53 (s7). However, this capacity was about 20\% lower than that of MIL-101 (s1). In contrast, the $\mathrm{CH}_{4}$ adsorption capacity of s4 was less than those of both MIL-53 and MIL-101.

As shown in Fig. 4, the breathing pressure (pressure at which the breathing effect started to occur) decreased as the synthesis time was increased. The existence of MIL-101 could affect the breathing of MIL-53 and prevent conversion from the NP to LP structure. When the synthesis time increased, the proportion of MIL-101 decreased, indicating that a lower pressure was required for this transformation.

The $\mathrm{CH}_{4}$ adsorption capacity of the hybrid material did not obey the BET specific surface area trend. The kinetic diameter of $\mathrm{CO}_{2}$ molecules was $0.33 \mathrm{~nm}$, while that of the $\mathrm{CH}_{4}$ molecules was $0.38 \mathrm{~nm}$. As the synthesis time was increased, some entrance diameters in the material might become smaller than the $\mathrm{CH}_{4}$ molecules. Therefore, the high $\mathrm{CO}_{2}$ and low $\mathrm{CH}_{4}$ adsorption capacities of $\mathrm{s} 4$ might be related to the size-selective mechanism of adsorption.

The well-known Langmuir model was used to fit the $\mathrm{CO}_{2}$ and $\mathrm{CH}_{4}$ isotherms of samples s1, s4, and s7. Using Matlab software (MathWork, Inc. R2012a), adjustable parameters of the Langmuir model were obtained for pure $\mathrm{CH}_{4}$ and $\mathrm{CO}_{2}$, as shown in Table 2. Notably, the first part of the $\mathrm{CO}_{2}$ adsorption isotherm (low pressure) was modeled for s4 and s7.

$$
q=q_{\mathrm{s} 1} \frac{b p}{1+b p}
$$

The results showed a good consistency of the fitted isotherm with the experimental data of MIL-101 $\left(R^{2}>0.99\right)$.

As the $\mathrm{CO}_{2}$ partial pressure was less than 5 bar in the conventional pressure swing adsorption (PSA) process, ${ }^{2}$ the lowpressure region of the $\mathrm{CO}_{2}$ isotherm could be used in binary adsorption modeling. EL and the IAST models were applied to evaluate the $\mathrm{CO}_{2} / \mathrm{CH}_{4}$ selectivity under binary gas mixtures at ambient temperature (298 K).

As expected, the EL selectivity for $\mathrm{CO}_{2} / \mathrm{CH}_{4}$ was constant (4.61, 59.34, and 12.47 , for s1, s4, and s7, respectively) for all gas compositions and over the entire pressure range. Sample s4 showed much higher selectivity for $\mathrm{CO}_{2} / \mathrm{CH}_{4}$ among the other samples. This high separation factor could have industrial applications. This enhancement in $\mathrm{CO}_{2} / \mathrm{CH}_{4}$ selectivity might be related to the increase in electrostatic interactions between the adsorbent and adsorbate (particularly polar $\mathrm{CO}_{2}$ molecules), and the size-selective exploitation due to narrowing of the pore and channel size in the hybrid samples, as observed in Fig. 3, and/or vacancy defects in the hybrid material. ${ }^{\mathbf{4 8 4} 9}$ Furthermore, the increased selectivity might be attributed to the increase in electrostatic field caused by the presence of two frameworks (MIL-101 and MIL-53). Therefore, a higher number of adsorbate-adsorbent interactions might be responsible for the uptake enhancement.

Using Matlab software, the IAST model, based on fitted parameters of the Langmuir equation for pure $\mathrm{CO}_{2}$ and $\mathrm{CH}_{4}$, was used to predict the selectivity of the binary mixture adsorption. The obtained $\mathrm{CO}_{2} / \mathrm{CH}_{4}$ selectivities and isotherms from the IAST models of different compositions and pressures (in the pressure range of 1-5 bar) are shown in Fig. 6.

The IAST and EL selectivity results were in agreement at low pressure. The IAST model results indicated that increasing the total pressure or $\mathrm{CO}_{2}$ composition increased the selectivity. At higher pressures, more $\mathrm{CO}_{2}$ molecules entered into the narrow pores of the hybrid sample, while some of the $\mathrm{CH}_{4}$ molecules were excluded due to having a kinetic size higher than the pore size. In low compositions, $\mathrm{CO}_{2}$ molecules needed to compete with $\mathrm{CH}_{4}$ molecules for available surface sites, which increased $\mathrm{CO}_{2}$ composition, resulting in higher selectivity.

Finally, the sorption results confirmed the beneficial effect of the hybrid material of MIL-53 and MIL-101 on $\mathrm{CO}_{2}$ separation from $\mathrm{CH}_{4}$. 

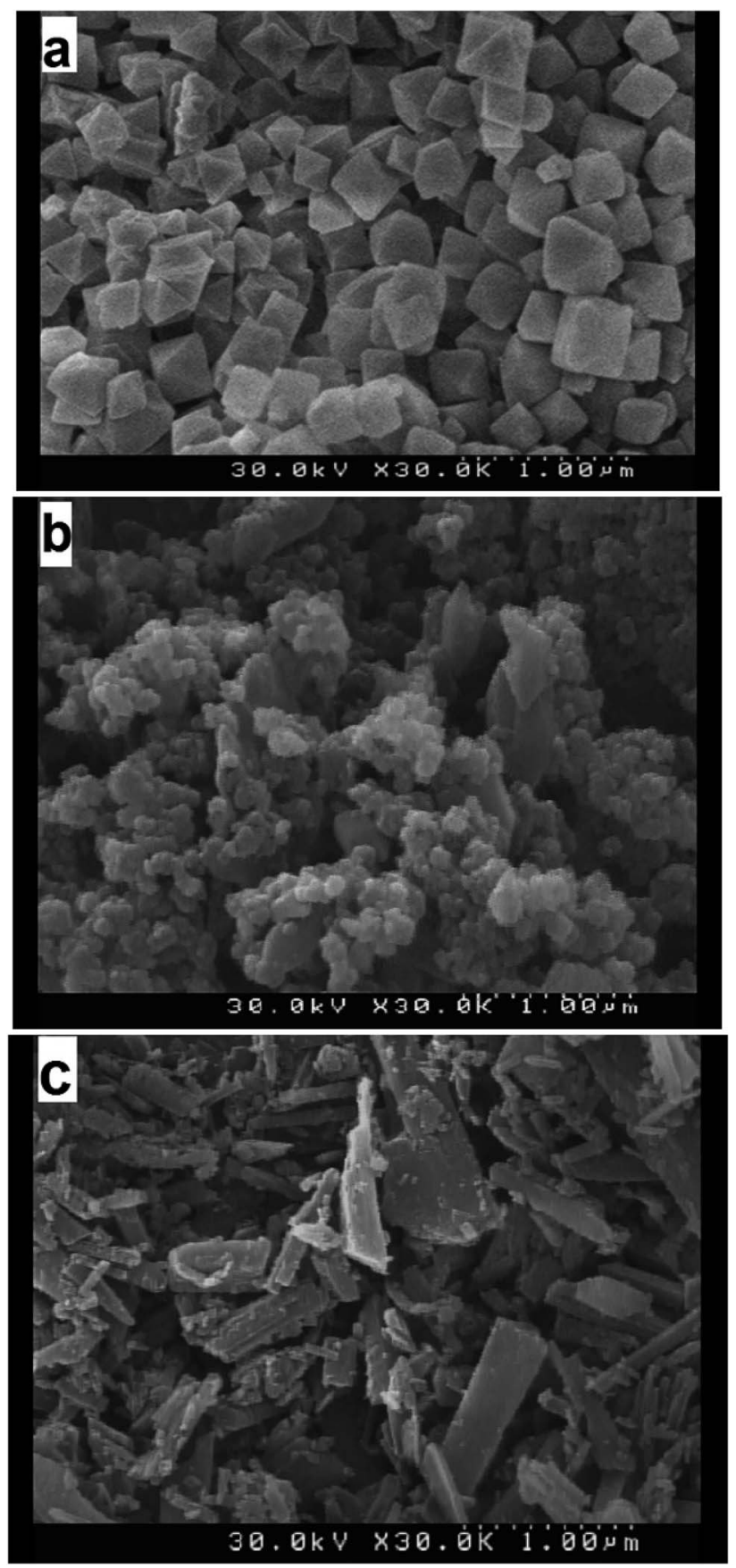

Fig. 8 SEM images of (a) s1, (b) s4, and (c) s7.

\subsection{Thermal stability}

Thermogravimetric analysis (TGA) results for the as-synthesized and calcined s4 samples are shown in Fig. 7. Three different steps were observed for as-synthesized s4. The first step, in the range $290-320{ }^{\circ} \mathrm{C}$, might be related to the departure of unreacted BDC trapped in the s4 structure. The second weight loss, at $400-430{ }^{\circ} \mathrm{C}$, might be related to the structural collapse of crystals and decomposition of MIL-101, which had lower thermal stability than MIL-53. The final step, in the range 480$520{ }^{\circ} \mathrm{C}$, might be related to the structural collapse of crystals and decomposition of MIL-53. Three steps were detected in s4
Table 3 Elemental analysis of the samples

\begin{tabular}{lllllll}
\hline & \multicolumn{2}{l}{ Element } & & & & \\
\cline { 2 - 6 } Samples & $\% \mathrm{Al}$ & $\% \mathrm{Cr}$ & $\% \mathrm{C}$ & $\% \mathrm{H}$ & $\% \mathrm{O}$ & $\% \mathrm{~F}$ \\
\hline s4 & 8.8 & 10.2 & 46.6 & 2.5 & 30.7 & 1.2 \\
s1 predicted & - & 21.67 & 40.07 & 2.24 & 33.36 & 2.64 \\
s1 observed & - & 20.8 & 41.78 & 2.37 & 32.63 & 2.42 \\
s7 predicted & 12.97 & - & 46.17 & 2.42 & 38.44 & - \\
s7 observed & 11.2 & - & 49.3 & 2.6 & 36.9 & -
\end{tabular}

after calcination. The calcined sample could adsorb moisture from the atmosphere. Therefore the first weight loss at around $100{ }^{\circ} \mathrm{C}$ was assigned to water departure, while the second and third steps at around 400 and $500{ }^{\circ} \mathrm{C}$ corresponded to elimination of the MIL-101 structure and the structural collapse of MIL-53, respectively.

Therefore, it was concluded that the MIL-53 and MIL-101 composite had enhanced thermal stability compared with that of MIL-101 within the hybrid material to around $400{ }^{\circ} \mathrm{C}$. The thermal stabilities of MIL-53 and MIL-101 have been reported to be about 500 and $275{ }^{\circ} \mathrm{C}$ in the literature..$^{26,30}$

\subsection{Morphology}

The morphologies of s1 (MIL-101), s4, and s7 (MIL-53) were observed by SEM, as shown in Fig. 8. The MIL-101 particles seemed to be rather small (diameter, about 100-500 nm) and similar in size, with all possessing a regular octahedral shape. MIL-53 had uniform sheet-like particles of sizes smaller than $1000 \mathrm{~nm}$.

The SEM image of s4 showed the texture variation of the hybrid material compared with the paternal MIL-101 and MIL53, exhibiting dense agglomeration of the hybrid of MIL-101 and MIL-53. The hybrid composite materials showed a disordered arrangement of MIL-53 embedded in elongated MIL-101 octahedral particles. Although MIL-101 did not prevent the formation of MIL-53, it modified the hybrid morphology and particle size. The presence of two different structures in the hybrid material imposed distortion forces on the crystal dimensions and the composite structure, which was also responsible for the small displacement in PXRD peak positions.

\subsection{Elemental analysis}

The results of elemental analysis are shown in Table 3. The ICP results showed that chromium and aluminum exist simultaneously in s4, while chromium was the only metal element present in s1, and aluminum was the only metal element present in $\mathrm{s} 7$.

\section{Conclusions}

Hybrid materials of MIL-101 and MIL-53 were synthesized using a hydrothermal method. The samples exhibited the characteristics of both MIL-101(Cr) and MIL-53(Al). MIL-101(Cr) did not prevent the formation of MIL-53(Al), but modified the morphology and particle size of the hybrid. The sample with the 
highest BET specific surface area showed about a 50\% enhancement in BET specific surface area compared with MIL$53(\mathrm{Al})$, but a decrease of about $20 \%$ compared with MIL-101(Cr). The thermal stability of the selected sample was greater than that of MIL-101(Cr), but lower than that of MIL-53(Al). The composition of MIL-101(Cr) and MIL-53(Al) enhanced the thermal stability of MIL-101(Cr) within the hybrid material to around $400{ }^{\circ} \mathrm{C}$.

The $\mathrm{CO}_{2}$ adsorption capacity of samples showed the same trend as that observed for BET surface area, while the $\mathrm{CH}_{4}$ adsorption capacity did not. The two-MOF hybrid had a higher $\mathrm{CO}_{2}$ adsorption capacity and much higher selectivity for $\mathrm{CO}_{2} /$ $\mathrm{CH}_{4}$ result from a higher affinity for $\mathrm{CO}_{2}$ compared with that for $\mathrm{CH}_{4}$ due to interactions through the open metal site of MIL-101 and hydroxyl groups of MIL-53. The high $\mathrm{CO}_{2}$ and low $\mathrm{CH}_{4}$ adsorption capacities of a selected sample were also related to the size-selective mechanism of adsorption. The IAST model results indicated that increasing the total pressure or $\mathrm{CO}_{2}$ composition increased the selectivity. The sorption experience demonstrated the beneficial effect of the MIL-53 and MIL-101 composition on $\mathrm{CO}_{2}$ separation from $\mathrm{CH}_{4}$.

The hybrid of MIL-53(Al) and MIL-101(Cr) is believed to provide a novel material with high thermal stability, adsorption capacity, and selectivity for $\mathrm{CO}_{2}$, which might be a promising material for PSA (pressure swing adsorption) processes.

\section{Conflicts of interest}

The authors declare no conflicts of interest.

\section{References}

1 Q. Sun, H. Li, J. Yan, L. Liu, Z. Yu and X. Yu, Renewable Sustainable Energy Rev., 2015, 51, 521.

2 P. Lestinsky, M. Vecer, P. Navratil and P. Stehlik, Clean Technol. Environ. Policy, 2015, 17, 1281.

3 J.-R. J. R. Li, Y. Ma, M. C. McCarthy, J. Sculley, J. Yu, H.-K. H. K. Jeong, P. B. Balbuena and H.-C. Zhou, Coord. Chem. Rev., 2011, 255, 1791.

4 Q. Wang, J. Luo, Z. Zhong and A. Borgna, Energy Environ. Sci., 2011, 4, 42.

5 F. Shieh, S. Wang, C. Yen, C. Wu, S. Dutta, L. Chou, J. Morabito, P. Hu, M. Hsu, K. Wu and C. Tsung, J. Am. Chem. Soc., 2015, 137, 4276.

$6 \mathrm{H}$. Lian, M. Hu, C. Liu, Y. Yamauchi and K. Wu, Chem. Commun., 2012, 48, 5151.

7 M. I. Nandasiri, S. R. Jambovane, B. P. Mcgrail, H. T. Schaef and S. K. Nune, Coord. Chem. Rev., 2016, 311, 38.

8 J. Liu, P. K. Thallapally, B. P. McGrail, D. R. Brown and J. Liu, Chem. Soc. Rev., 2012, 41, 2308.

9 G. Férey, Chem. Soc. Rev., 2008, 37, 191.

10 N. Stock and S. Biswas, Chem. Rev., 2012, 112, 933.

11 A. Taheri, E. G. Babakhani and J. Towfighi Darian, Energy Fuels, 2017, 31, 8792.

12 S. Natarajan, P. Mahata and D. Sarma, J. Chem. Sci., 2012, 124, 339.
13 A. Taheri, E. G. Babakhani and J. Towfighi, J. Nat. Gas Sci. Eng., 2017, 38, 272.

14 A. Taheri, E. G. Babakhani and J. Towfighi, Adsorpt. Sci. Technol., 2017, 53, 247.

15 O. Kozachuk, M. Meilikhov, K. Yusenko, A. Schneemann, B. Jee, A. V. Kuttatheyil, M. Bertmer, C. Sternemann, A. Pöppl and R. a. Fischer, Eur. J. Inorg. Chem., 2013, 4546.

16 N. A. Khan and S. H. Jhung, Cryst. Growth Des., 2010, 10, 1860.

17 J. Mowat, S. Miller and A. Slawin, Microporous Mesoporous Mater., 2011, 142, 322.

18 G. Férey, C. Mellot-Draznieks, C. Serre, F. Millange, J. Dutour, S. Surblé and I. Margiolaki, Science, 2005, 309, 2040.

19 S. Biswas, S. Couck, M. Grzywa, J. F. M. Denayer, D. Volkmer and P. Van Der Voort, Eur. J. Inorg. Chem., 2012, 2481.

20 J. a. Mason, L. E. Darago, W. W. Lukens and J. R. Long, Inorg. Chem., 2015, 54, 10096.

21 C. Serre, F. Millange, C. Thouvenot, M. Noguès, G. Marsolier, D. Louër and G. Férey, J. Am. Chem. Soc., 2002, 124, 13519.

22 U. Mueller, M. Schubert, F. Teich, H. Puetter, K. SchierleArndt and J. Pastré, J. Mater. Chem., 2006, 16, 626.

23 R. J. Kuppler, D. J. Timmons, Q.-R. Fang, J.-R. Li, T. a. Makal, M. D. Young, D. Yuan, D. Zhao, W. Zhuang and H.-C. Zhou, Coord. Chem. Rev., 2009, 253, 3042.

24 S. Bhattacharjee, C. Chen and W.-S. Ahn, RSC Adv., 2014, 4, 52500.

25 D. Farrusseng, Metal-Organic Frameworks: Applications from Catalysis to Gas Storage, Wiley-VCH, Weinheim, Germany, 1st edn, 2011.

26 D. Y. Hong, Y. K. Hwang, C. Serre, G. Férey and J. S. Chang, Adv. Funct. Mater., 2009, 19, 1537.

27 A. Uzun and S. Keskin, Prog. Surf. Sci., 2014, 89, 56.

28 P. Chowdhury, S. Mekala, F. Dreisbach and S. Gumma, Microporous Mesoporous Mater., 2012, 152, 246.

29 T. Loiseau, C. Serre, C. Huguenard, G. Fink, F. Taulelle, M. Henry, T. Bataille and G. Férey, Chem. -Eur. J., 2004, 10, 1373.

30 J. H. Cavka, S. Jakobsen, U. Olsbye, N. Guillou, C. Lamberti, S. Bordiga and K. P. Lillerud, J. Am. Chem. Soc., 2008, 130, 13850.

31 D. V. Patil, P. B. S. Rallapalli, G. P. Dangi, R. J. Tayade, R. S. Somani and H. C. Bajaj, Ind. Eng. Chem. Res., 2011, 50, 10516.

32 W. P. Mounfield and K. S. Walton, J. Colloid Interface Sci., 2015, 447, 33.

33 Q.-L. Zhu and Q. Xu, Chem. Soc. Rev., 2014, 43, 5648.

34 M. Tagliabue, D. Farrusseng, S. Valencia, S. Aguado, U. Ravon, C. Rizzo, A. Corma and C. Mirodatos, Chem. Eng. J., 2009, 155, 553.

35 P. Rallapalli, D. Patil, K. P. Prasanth, R. S. Somani, R. V. Jasra and H. C. Bajaj, J. Porous Mater., 2010, 17, 523.

36 N. A. Khan, J. W. Jun and S. H. Jhung, Eur. J. Inorg. Chem., 2010, 1043.

37 M. Eddaoudi, D. B. Moler, H. Li, B. Chen, T. M. Reineke, M. O'Keeffe and O. M. Yaghi, Acc. Chem. Res., 2001, 34, 319. 
38 R. Haldar, N. Sikdar and T. K. Maji, Mater. Today, 2015, 18, 97.

39 E. Haque, J. H. Jeong and S. H. Jhung, CrystEngComm, 2010, $12,2749$.

40 M. Thommes, K. Kaneko, A. V. Neimark, J. P. Olivier, F. Rodriguez-Reinoso, J. Rouquerol and K. S. W. Sing, Pure Appl. Chem., 2015, 87, 1051.

41 K. Morishige and M. Ito, J. Chem. Phys., 2002, 117, 8036.

42 M. Alhamami, H. Doan and C.-H. Cheng, Materials, 2014, 7, 3198.

43 Y. Zhang, W. Su, Y. Sun, J. Liu, X. Liu and X. Wang, J. Chem. Eng. Data, 2015, 60, 2951.
44 A. Boutin, F. Coudert, M. Huet, A. Neimark, G. Ferey and A. Fuchs, J. Phys. Chem. C, 2010, 114, 22237.

45 S. Zheng, X. Zhao, S. Lau, A. Fuhr, P. Feng and X. Bu, J. Am. Chem. Soc., 2013, 135, 10270.

46 C. Wiktor, M. Meledina, S. Turner, O. Lebedevd and R. Fischer, J. Mater. Chem. A, 2017, 5, 14969.

47 C. Janiak and J. K. Vieth, New J. Chem., 2010, 34, 2366.

48 Z. Fang, B. Bueken, D. E. De Vos and R. A. Fischer, Angew. Chem., Int. Ed., 2015, 54, 7234.

49 D. S. Sholl and R. P. Lively, J. Phys. Chem. Lett., 2015, 6, 3437. 